\title{
Peer-Led Group Tele-Supervision of Clinical Psychologists: Optimization of Resources - A Malaysian Case Study
}

Umi Izzatti Saedon ${ }^{1}$, Nicholas Pang Tze Ping ${ }^{2}$, Loo Jiann Lin ${ }^{3 *}$

${ }^{1}$ Department of Psychiatry and Mental Health, Raja Perempuan Zainab II Hospital, Kelantan, Malaysia

${ }^{2}$ Department of Community and Family Medicine, Faculty of Medicine and Health Sciences, Universiti Malaysia Sabah, Kota Kinabalu, Sabah, Malaysia

${ }^{3}$ Department of Medical Education, Faculty of Medicine and Health Sciences, Universiti Malaysia Sabah,

Kota Kinabalu, Sabah, Malaysia

\section{*Corresponding author's email: jiannlinl00@gmail.com}

Received: 7 May 2019

Accepted: 7 October 2019

\section{Keywords:}

supervision, peer supervision, tele-supervision, group supervision, psychotherapy

\section{ABSTRACT}

Inaccessibility to clinical supervision is an issue faced by solo clinical psychologist practitioners. Combination use of web-based instant messaging and video call application were tried by 28 clinical psychologists in conducting a peer-led group tele-supervision to address ethical dilemmas, discuss case management, provide technical instruction, explore resistance and analyse countertransference, provide emotional support, and share knowledge and updated guidelines. Despite facing challenges including difficulty in face-to-face session scheduling, limited time for in-depth discussion, internet connection issues, and documentation dilemma, we believe it has potential to influence supervision practice for clinicians working in isolation in rural or remote locations.

\section{INTRODUCTION}

Clinical supervision is a meeting where supervisees discuss, review and reflect on their work with a supervisor. This results in experiential learning and improvement in practice'. For supervision to be beneficial, close monitoring, opportunities to model competence, specific instructions, clear goals, and feedback on performance are essential ${ }^{2}$. Conventional face-to-face supervision may not be readily accessible for isolated clinical psychologists if travelling distances are far. This problem is shared by clinical psychologists in the Malaysian public healthcare setting, as most state tertiary hospitals have only one clinical psychologist. 
With the advancement of information technology, a variety of applications are available to assist this process, including webbased instant messaging ${ }^{3,4}$. Incorporation of technology into clinical supervision has significantly removed geographical barriers ${ }^{5}$. Different tele-supervision efforts have been tried in different regions of the world with largely positive response although larger prospective studies are still required, including the cost-effectiveness ${ }^{6}$.

In this article, the authors describe a case study from Malaysia, considering their personal experience of using a combination of web-based instant messaging applications and video call applications in conducting peerled group tele-supervision among clinical psychologists.

\section{The Initiative of Peer-led Tele-Supervision Platform}

WhatsApp ${ }^{\text {TM }}$ (instant messenger), Zoom ${ }^{\text {TM }}$ (video or audioconference call) and Skype ${ }^{\mathrm{TM}}$ (video or audioconference call) were used by 28 clinical psychologists from Malaysia for the purpose of organizing peer-group telesupervision. First, a core WhatsApp ${ }^{\mathrm{TM}}$ group was set up in October 2017 for text-based discussion while online face-to-face sessions were conducted using either Skype ${ }^{\mathrm{TM}}$ or Zoom $^{\text {TM }}$ every three months. Each session lasted around three hours with at least four participants. Case summaries and issues for discussion would be submitted a week prior to the online meeting with specific caution taken to maintain patient confidentiality.
Discussions during the tele-supervision covered the following areas:

1. Ethical dilemmas

2. Case assessment and management

3. Technical support

4. Resistance and countertransference analysis

5. Emotional support

6. Knowledge sharing and update of guidelines

\section{Ethical Dilemmas}

Common ethical dilemmas brought for discussion included the conflict between the duty of care and confidentiality as well as law-related concerns, e.g. issues related risk of self-harm or harming others, rape, underage sex, and domestic violence. The discussion in WhatsApp ${ }^{\mathrm{TM}}$ to get others' opinion has significantly reduced the anxiety faced by solo clinical psychologists as there is a collective opinion on such pressing issues. While discussing these clinical cases with ethical dilemmas on the virtual platform, the similar principle of confidentiality needed to be upheld ${ }^{7,8}$.

\section{Case Assessment and Management}

Clinical psychologists with limited numbers of psychological tools feel overwhelmed when more comprehensive psychological assessment is needed. Such cases were discussed in tele-supervision and referral to the nearest clinical psychological services which had the needed psychological tools could be made, which inculcates a collaborative spirit. 


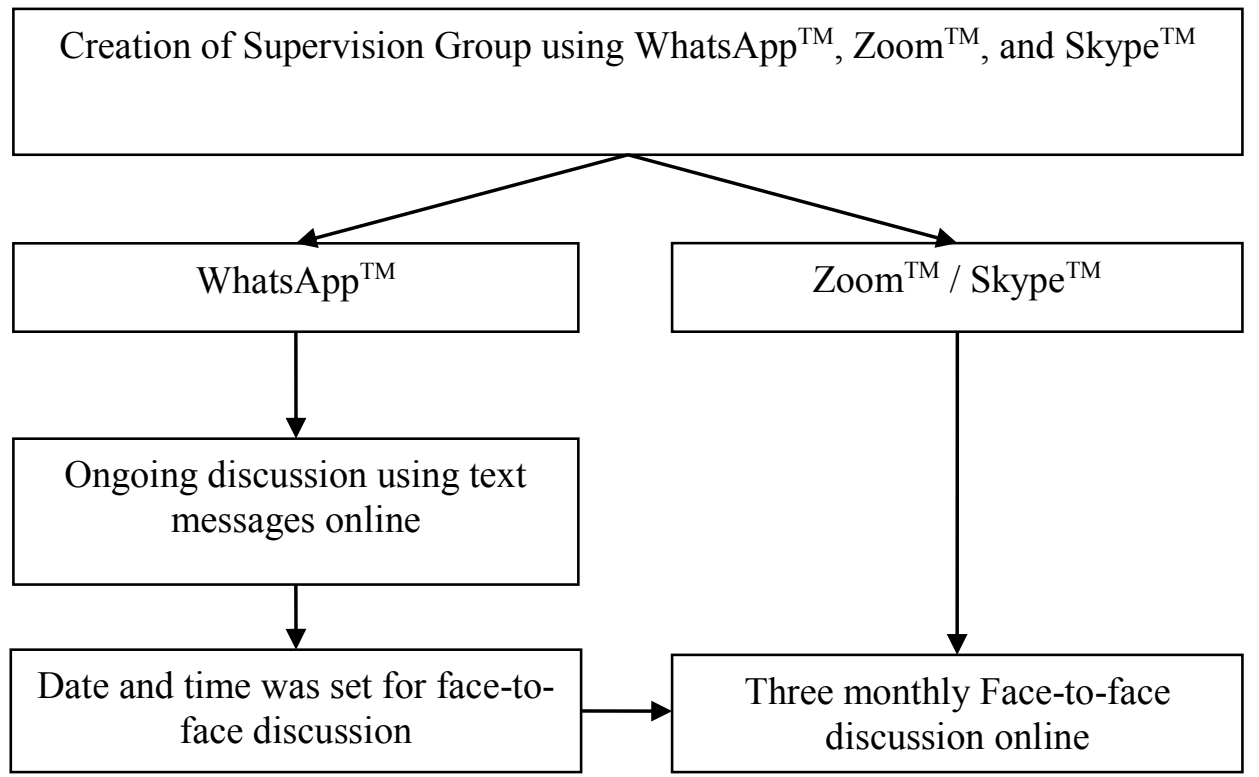

Figure 1 Flowchart of tele-supervision group using different virtual platforms

\section{Technical Support}

As familiarity with specific assessment procedures or therapy protocols depends on the exposure during training, this telesupervision group provides additional accessible and supportive guidance and technical support for a range of assessment and therapeutic methods, which help in competency improvement and monitoring.

\section{Resistance and Countertransference Analysis}

Resistance and countertransference can happen while dealing with complicated cases, including borderline personality disorder ${ }^{9}$. The WhatsApp ${ }^{\mathrm{TM}}$ group allows cases to be dissected from different angles and perspectives. By having input from peers through different platforms, a solo clinical psychologist can share his or her thoughts.

\section{Emotional Support}

One of the most daunting parts of being a solo clinical psychologist is the feeling of fighting the war alone as described by some of the practitioners. Having an active WhatsApp ${ }^{\mathrm{TM}}$ message and regular face-to-face meeting helps the solo clinical psychologist feel more supported.

\section{Knowledge Sharing and Update of Guidelines}

The up-to-date practice is recommended to ensure the best outcome for patients although it is difficult for a solo clinical psychologist to keep abreast with all the latest developments. With different participants being delegated to different learning topics, new and updated guidelines can be summarised and shared among group members.

\section{The Benefit of the Approach}

This tele-supervision shared the benefit of group supervision, including multiple feedback sources, chances for networking, different perspectives for one issue, learning through observation, learning how to lead a discussion, and improvement of presentation skills ${ }^{10}$. Removal of temporal and geographical restrictions was one of the strengths of this approach. No extra cost was incurred other than the mobile network package. 


\section{Challenges Faced}

It can be challenging to get suitable time for face-to-face discussions during office hours. Hence, some of the online teleconference meetings took place after office hours.

A high number of cases that required input limited the depth of the discussion. Balancing the breadth and depth of input given for each case was a challenging job. Fortunately, some relatively less complicated case could be discussed through WhatsApp ${ }^{\top M}$ text messages and discussion of one case also provided solutions for other cases.

The flow of discussion relies on the quality of the internet connection too. The sudden disappearance of a participant from the face-to-face discussion was not an uncommon phenomenon. In addition to that, the sound quality was another important factor that disturbed the flow of the supervision process.

As there is no existing policy in Malaysia regulating this form of clinical tele-supervision, documentation of the conclusion of discussion in the patient's note can be a dilemma. The medicolegal standing of the results of discussions is still uncertain until a legal framework is implemented. Nevertheless, documentation of clinical supervision is encouraged as it has several important values, such as helping in tracking the progress of professional development ${ }^{11}$.

\section{CONCLUSION}

Peer-led group tele-supervision is an additional platform for work resources and psychosocial support among clinical psychologists, which promotes collaborative practice and improves the quality of service. Its low-cost nature makes it feasible to be expanded to rural and remote places or resource deprived region. More structured and larger prospective studies need to be conducted to evaluate the efficiency of this model of peer-led group tele-supervision.

\section{ACKNOWLEDGEMENTS}

The authors would like to thank everyone who has supported the process of this manuscript preparation.

\section{CONFLICT OF INTEREST}

The authors declare that they have no competing interests in publishing this case.

\section{ETHICAL APPROVAL}

Ethical approval was obtained from the Ethical Review Committee of Universiti Malaysia Sabah on 15 December 2017 (Reference number UMS/FPSK6.9/100-6/1/95). A copy of the approval is available for review by the Chief Editor.

\section{REFERENCES}

1. Carroll M. (2007). One more time: What is supervision? Psychother Aust 13 (3): 34 - 40.

2. Milne D, James I. (2000). A systematic review of effective cognitive-behavioural supervision. Br J Clin Psychol 39 (2): 111 127. DOI: $10.1348 / 014466500163149$

3. Loo JL, Koh EB, Pang NT, Nor Hadi NM. (2016). Use of WhatsApp in assisting psychiatry learning. Med Educ 50 (11): 1165. DOI: 10.1111/medu.13195

4. Bruce T, Byrne F, Kemp L. (2018). Using Skype to support remote clinical supervision for health professionals delivering a sustained maternal early childhood programme: A phenomenographical study. Contemp Nurse 54 (1): 4 - 12. DOI: 10.1080/10376178.2018.1441732

5. Loo JL, Ang JK, Subhas N et al. (2017). Learning psychodynamic psychotherapy in Southeast Asia. Psychodyn Psychiatry 45 (1): 47 - 57. DOI: 10.1521/pdps.2017.45.1.45

6. Martin P, Lizarondo L, Kumar S. (2017). A systematic review of the factors that influence the quality and effectiveness of telesupervision for health professionals. J Telemed Telecare 24 (4): 271 - 281. DOI: $10.1177 / 1357633 \times 17698868$ 
7. Gamble N, Boyle C, Morris ZA. (2015). Ethical Practice in Telepsychology. Aust Psychol 50 (4): 292 - 298. DOI: 10.1111/ap.12133

8. Deane FP, Gonsalvez C, Blackman RJ et al. (2015). Issues in the development of e-supervision in professional psychology: A review. Aust Psychol 50 (3): 241 - 247. DOI: 10.1111/ap.12107

9. Merced M. (2015). The beginning psychotherapist and borderline personality disorder: Basic treatment principles and clinical foci. Am J Psychother 69 (3): 241 268.
10. Valentino $A L$, LeBlanc $L A$, Sellers TP. (2016). The benefits of group supervision and a recommended structure for implementation. Behav Anal Pract 9 (4): 320 - 328. DOI: 10.1007/s40617-016-0138-8

11. Barnett JE, Molzon CH. (2014). Clinical supervision of psychotherapy: Essential ethics issues for supervisors and supervisees. J Clin Psychol 70 (11): 1051 - 1061. DOI: 10.1002/jclp.22126 
